\title{
Entre a revelação e 0 atendimento: família e abuso sexual
}

\author{
Between Revelation and First Care: Family and Sexual fbuse \\ Entre la revelación y la atención: familia y abuso sexual
}

\author{
Marlene Magnabosco Marra* \\ Liana Fortunato Costa* \\ Universidade de Brasilia, Brasília, Brasil. \\ Programa de Pós Graduação em Psicologia Clínica e Cultura do Instituto \\ de Psicologia da Universidade de Brasília
}

Doi: http://dx.doi.org/10.12804/revistas.urosario.edu.co/apl/a.3564

\section{Resumo}

Há um intervalo de tempo entre a ocorrência do abuso sexual e seu desvelamento dentro da família, do qual se tem pouco conhecimento. O objetivo deste texto é compreender o que ocorre com as famílias no período entre a revelação do abuso sexual e o início do atendimento especializado. O contexto de pesquisa foi uma instituição pública, na qual foram realizadas dez entrevistas com nove famílias que apresentavam situação de abuso sexual. Resultados dividem-se entre informações sobre a configuração familiar e o período de tempo no qual há um silenciamento sobre a situação do abuso sexual, anterior à publicização da violência: 1) Sobre a configuração familiar - as mães estão presentes na maioria das famílias, o abuso sexual intrafamiliar prevalece sobre o extrafamiliar, e a maioria das vítimas é de meninas, sendo que idade média é de 8 anos e 8 meses. 2) Sobre o período de tempo entre a revelação do abuso sexual e o atendimento - o abuso sexual ocorreu, em média, 27 meses antes do momento da entrevista na instituição; o tempo médio da ocorrência do abuso sexual é de 13 meses antes da sua revelação; e o intervalo de tempo que vai da revelação do abuso sexual à denúncia é de 7 meses. A revelação do abuso sexual é percebida, pela família, como mais uma ameaça aos outros acontecimentos com os quais a família já se depara, gerando reações paradoxais que vão desde a proteção à imobilidade. Quando as famílias se apresentam para o atendimento institucional, encontram-se confusas e distanciadas da situação de violência. O tempo entre o abuso sexual, a revelação e a busca por ajuda é vivido em interação familiar, necessitando ser visto mais como momento de elaboração e assimilação da violência sofrida.

Palavras-chave: violência na família, abuso sexual, intervenção psicossocial, aconselhamento.

\section{Abstract}

There is a time interval between the sexual abuse itself and its revelation in the family. There is little knowledge about this time period. The goal of this research

* Marlene Magnabosco Marra, Liana Fortunato Costa, Universidade de Brasília, Brasília, Brasil.

Correspondência a respeito deste artigo deve ser endereçada para Marlene Magnabosco Marra. SGAS 910 Conjunto B Bloco D sala 227 - Asa Sul 70390-100 Brasília/DF. Correio eletrônico: marlenemarra1@gmail.com

Cómo citar este artículo: Magnabosco Marra, M. \& Fortunato Costa, L. (2018). Entre a revelação e o atendimento: família e abuso sexual. Avances en Psicología Latinoamericana, 36(3), 459-475. DOI: http://dx.doi.org/10.12804/revistas.urosario.edu. co/apl/a.3564 
was to understand what happens with the families in the period between the revelation of sexual abuse and the start of the specialized first care. The research took part in a public institution where ten interviews were conducted with nine families that lived a situation of sexual abuse. The results were divided between information about family configuration and the period of time in which there was silence about the situation of sexual abuse before it actually became known: 1) About the family configuration: mothers are present in most of the families with the intra-familial sexual abuse taking precedence over the extra-familial; most of the victims are girls of an average age of 8 years and 8 months. 2) About the period of time between the revelation of sexual abuse and the first care: the sexual abuse happened on average 27 months before the interview at the institution; the average time of the sexual abuse itself is 13 months before its revelation; and the time interval from the revelation of sexual abuse to its denouncement is 7 months. The revelation of sexual abuse is perceived by the family as an additional threat to all the other predicaments with which the family sees itself confronted, originating paradoxical reactions that range from protection to immobility. When families seek out the health care institution they are confused and distanced from the situation of violence in which they live. The time between the sexual abuse, the revelation, and the search for help depends on the family interaction and needs to be seen more as a time for elaboration and coming to terms with the experience that they are suffering.

Keywords: Violence in the family, sexual abuse, psychosocial intervention, counselling.

\section{Resumen}

Hay un intervalo de tiempo entre el hecho del abuso sexual y su desvelamiento, que ocurre dentro de las familias en el periodo entre la revelación del abuso sexual y el inicio de la atención especializada. El contexto de investigación fue una institución pública, donde fueron realizadas diez entrevistas con nueve familias que presentaban situación de abuso sexual. Los resultados se dividen entre informaciones sobre la configuración familiar y el periodo de tiempo en el cual hay un silenciamiento sobre la situación del abuso sexual, anterior a la divulgación del acto violento: 1) sobre la configuración familiar: las madres están presentes en la mayoría de las familias, el abuso sexual intrafamiliar prevalece sobre el extrafamiliar, y casi todas las víctimas son niñas, siendo la edad promedio de 8 años y 8 meses; 2) sobre el periodo de tiempo entre la revelación del abuso sexual y la atención: el abuso sexual ocurrió, en promedio, 27 meses antes del momento de la entrevista en la institución; el tiempo promedio del hecho del abuso sexual es de 13 meses antes de su revelación, y el intervalo de tiempo que hay de la revelación del abuso sexual a la denuncia es de 7 meses. La revelación del abuso sexual es percibida por la familia más como una amenaza a los otros acontecimientos con los cuales la familia ya se enfrenta, generando reacciones paradoxales que van desde la protección a la inmovilidad. Cuando las familias se presentan para la atención institucional, se encuentran confundidas y distanciadas de la situación de violencia. El tiempo entre el abuso sexual, la revelación y la búsqueda de ayuda es vivido en interacción familiar, pero se necesita que sea visto como un momento de elaboración y asimilación de la violencia sufrida.

Palabras clave: violencia en la familia, abuso sexual, intervención psicosocial, consejería.

\section{Introdução}

A construção do conhecimento e a investigação acerca das vivências de abuso sexual de crianças e adolescentes na família vêm sendo largamente desenvolvida. Esse acúmulo de conhecimento tem favorecido ao Estado a construção de Políticas Públicas dedicada à intervenção e tratamento das vítimas. Porém, poucos estudos vêm se dedicando a investigar a dimensão qualitativa do que ocorre com as vítimas e suas famílias no período pós-revelação da violência sexual até o momento no qual recebem atendimento psicossocial. 
São muitas as dificuldades relacionadas ao processo de revelação e diversos estudos internacionais como Frías e Erviti (2014), Sigurdardottir, Halldorrsdottir e Bender (2014), Hershkowits, Lanes e Lamb (2007) e Plummer (2006) abordam as justificativas pelas quais as vítimas negam o fato ou postergam o tempo de revelação. Pesquisas nacionais como Baia, Veloso, Habigzang, Dell'Aglio, D. D. \& Magalhães, (2015), Costa, Junqueira, Meneses \& Stroher (2013) exploram principalmente aspectos relacionados às dificuldades de notificação do abuso sexual, dificuldades enfrentadas pelos profissionais que atuam nesta área e discutem o que se passa com a vítima. Atualmente, pouco se sabe sobre o que ocorre com as famílias e as vítimas enquanto ainda não se estabeleceram ações de cuidado, proteção e responsabilização nesse cenário.

Uma exceção é Santos \& Dell'Aglio (2010) sustentam, a partir de seus estudos, como o processo de revelação e notificação do abuso sexual rompe com o equilíbrio da família. Costa, Penso, Rufini, Mendes e Borba (2007) chamam atenção para a falta de acompanhamento a essas famílias no período em que ocorre a revelação/notificação e antes do atendimento. Nesse tempo em que aguardam atendimento, muitas famílias se veem sozinhas para lidar com todas as ameaças, perturbações e alterações no sistema familiar causados pela revelação. O processo vivido entre o tempo que transcorre da revelação ao atendimento é muitas vezes desarticulado das redes de, proteção gerando ações fragmentadas e muitas vezes emergenciais.

O abuso sexual é uma das formas mais graves de violência contra crianças e adolescentes, geradora de efeitos negativos para o desenvolvimento das vítimas, deixando consequências físicas, emocionais, sociais e psicológicas e tem sua expressão mais frequente no contexto intrafamiliar. $\mathrm{O}$ abuso sexual é definido como o envolvimento de uma criança ou adolescente em atividade sexual, da qual não entende e não dá o consentimento e para qual não está preparada, em função de seu estágio de desenvolvimento. Quase sempre é perpetrado por uma pessoa que cuida e que está em uma relação de responsabilidade, confiança ou força com a criança, sendo que a atividade é destinada para gratificação ou satisfação das necessidades desta outra pessoa (Word Health Organization, 1999).

Estima-se que a cada ano no Brasil 0.26\% da população sofre violência sexual, o que indica que haja anualmente 527 mil tentativas ou casos de estupros consumados no país, dos quais $10 \%$ são reportados à polícia. Tal informação é consistente com os dados do Anuário do Fórum Brasileiro de Segurança Pública (FBSP, 2013) que apontou que em 2012 foram notificados 50617 casos de estupro no Brasil. A frequência tem variado de três a $29 \%$ nos homens e de sete a $36 \%$ nas mulheres.

Este texto enfoca informações obtidas durante o processo de acesso ao campo de uma pesquisa qualitativa, que buscou a caracterização de algumas famílias no intervalo de tempo entre o momento em que se dá a revelação do abuso sexual e o momento no qual a família busca atendimento especializado. O objetivo específico do texto é compreender o que ocorre com as famílias no período entre a revelação do abuso sexual e o início do atendimento especializado. Como a família se organiza neste período? O que ocorre com a família e a vítima nesse intervalo de tempo? Como a família, ainda sem ajuda de profissionais especialistas, prossegue em sua rotina de vida? Qual significado é dado pela família a esse período de tempo? Essas são algumas questões que nortearam as pontuações enunciadas no presente artigo.

\section{Da revelação ao atendimento: aspectos teóricos}

É no momento da revelação do abuso sexual que os aspectos relativos à condição hierárquica submissa da criança em relação ao adulto são percebidos, de forma subjetiva, tanto para cada membro da família quanto para a vítima. É nesse momento, ainda, que a violência se torna pública, saindo do 
contexto privado. Nesse processo, a revelação é o primeiro e mais importante passo no qual a vítima conta para alguém sobre a violência que sofreu ou vem sofrendo, dando oportunidade para que a notificação seja decretada, alcançando relações extrafamiliares, assim como o interesse público.

A década de 1980 é marcada pelos primeiros estudos sobre a temática da revelação, que enfatizaram a importância de se compreender o momento da revelação como um processo. Ao mobilizar diferentes sentimentos, a revelação se torna um momento delicado, que pode ocorrer de forma intencional, quando a criança ou o adolescente já tomou a decisão sobre para quem contar; ou de forma acidental. Com essa segunda postura, a vítima vai construindo a possibilidade de relatar o abuso, deixando escapar elementos que compõem a situação, mostrando para a pessoa escolhida para a revelação o quanto aquela situação tem aspectos intrusivos (Lovett, 2004; Plummer, 2006; Hershkowits et al., 2007; Marra, 2016).

Diferentes autores (Costa et al., 2007; Jensen, Gulbrandsen, Mossige, Reichelt \& Tjerslandd, 2005; Santos \& Dell'Aglio, 2010) compreendem o processo da revelação em três momentos distintos, gerando também sentimentos distintos: antecedentes, revelação propriamente dita e repercussões da revelação. Na pré-revelação, estão presentes as vivências de fantasias, sentimentos e expectativas quanto às consequências da revelação. A vítima faz um julgamento com relação ao que viveu com o abusador, ao fato de não ter conseguido dizer não e aos significados que atribui a isso. A criança ou adolescente vitimado avaliam também os sentimentos e sensações boas ou ruins vivenciados na situação do abuso sexual. O segundo momento é o da revelação propriamente dita, que inclui a decisão de como e para quem contar. A vítima escolhe alguém de sua confiança, estabelecendo com esta pessoa um sentimento de proximidade. O terceiro momento do processo (repercussões $d a$ revelação), agora já público, apresenta as consequências que advém do fato de a vítima ter desvelado o segredo. À medida que a narrativa da vítima se torna pública, surgem os desdobramentos que podem ajudar ou atrapalhar o processo que se segue, mobilizando o aparecimento de crises na família nuclear e extensa (Hershkowit et al., 2007; Santos \& Dell'Aglio, 2010).

Com relação ao tempo de espera para atendimento e possíveis repercussões para as famílias, autores como Serafim, Saffi, Achá e Barros, (2011), Habigzang e Koller, (2011), Passarela, Mendes e Maril (2010) e Clark, Caldwell, Power e Stansfeld (2010) enfatizam que esta situação de violência provoca danos por muitas vezes irreparáveis. Nesse sentido, a vítima requer ajuda o quanto antes para enfrentamento do sofrimento. Porém, a ajuda especializada somente será procurada quando esses traumas emocionais e psicológicos vierem a se agravar. Para esses autores, o que mais chama a atenção é que a vítima, na maioria das vezes, não encontrará em um primeiro momento uma situação favorecedora para a sua denúncia. No ambiente familiar, quando identificado como o lócus da violência, a vítima se sente emocionalmente perseguida, violada, assustada, abandonada e desprotegida pelo mundo que a rodeia. As vivências de medo e desamparo se traduzem em dificuldades como consequência dos parcos recursos internos próprios da faixa etária em que se situam a criança e o adolescente. Furniss (2002) aponta que a revelação do abuso sexual contra a criança conduz a uma crise imediata nas famílias, trazendo grandes perturbações.

\section{Método}

O contexto desta pesquisa é o Centro de Referência Especializado de Assistência Social - Creas- (Resolução n. ${ }^{0} 109$, de 11 de Novembro de 2009), de uma grande capital. Os serviços prestados às famílias e aos indivíduos no âmbito da assistência social no Brasil ocorrem com base na estrutura apresentada pela Política Nacional de Assistência Social —PNAS - (2004), e pela Lei do Sistema 
Único de Assistência Social — SUAS- (2011). Os casos de abuso sexual são atendidos pelos Creas segundo orientação da Tipificação Nacional dos Serviços Socioassistenciais (MDS, 2009). Para a discussão das informações obtidas, adotou-se um estudo de corte transversal, estatístico descritivo dos dados primários obtidos nas entrevistas e dados secundários obtidos dos prontuários do Creas onde as entrevistas foram realizadas.

As famílias sujeitos dessa pesquisa encontram-se em situação de extrema pobreza; exclusão social e vivências de desigualdades de oportunidades; dificuldades ao acesso a serviços de saúde e educacionais; situações de gravidez e vivências de relações sexuais fora de uma união formal; cujos adultos têm um baixo índice de escolaridade, não atingindo o término do ensino fundamental, com $15 \%$ de analfabetos, uma renda de em torno 160.00/família e 75\% das famílias são beneficiárias da bolsa família e outras ajudas vindas de programas do governo.

Foram realizadas 10 entrevistas com nove famílias no período compreendido entre os meses de janeiro e março de 2013. Segundo o cronograma da instituição, este período é o momento no qual as famílias são acolhidas com o intuito de proceder à organização do atendimento psicossocial que virá a seguir. Todas as famílias aqui descritas apresentaram situação de abuso sexual e chegaram à instituição por meio de demanda espontânea, ou por meio de encaminhamento do sistema justiça. Uma família foi entrevistada duas vezes, em razão de necessidade de maior tempo para compreensão da história de abuso sexual.

A aproximação ao campo de pesquisa se deu com o objetivo de conhecer as demandas existentes na instituição. $\mathrm{O}$ acesso aos sujeitos durante esse período ocorreu, principalmente, por meio de entrevistas de acolhimento, que tiveram como objetivos: o estabelecimento de vínculo da família com a instituição; a orientação sobre o programa específico para situação de abuso sexual; e o esclarecimento sobre o motivo do encaminhamento.
Sabe-se que o período de tempo entre a revelação e a mobilização da família para a busca de atendimento pode abranger até dois anos ou mais (Costa et al., 2007). O acesso ao campo ocorreu durante o ano de 2013, no qual houve participação das pesquisadoras nas atividades da instituição, em especial nas supervisões clínicas.

Cada entrevista teve duração aproximada de uma hora e meia. A entrevista consistiu de perguntas abertas para que a família pudesse narrar suas histórias de violência familiar. O roteiro norteador consistiu dos seguintes itens: - 1) Gostaria que vocês se apresentassem. É a primeira vez que estão aqui? Já estiveram em atendimento antes? -2) Vocês têm alguma ideia do que vamos conversar hoje? Que história vocês vão nos contar sobre essa família quando descobriram a violência, o abuso sexual? -3) Como a família estava vivendo neste momento? Como foram vivendo com essa violência, uma vez que já sabiam do que tinha acontecido? - 4) E agora que vocês vão receber atendimento aqui no Creas, como está essa família? Como vocês se sentem sabendo que serão atendidos pelos profissionais do Creas, para tratar da questão do abuso sexual? O que esperam ou imaginam que irá mudar em suas vidas? -5) Vocês gostariam de me contar mais alguma coisa?

Este roteiro foi apresentado a todos os membros da família presentes na entrevista, inclusive a vítima. Buscou-se levantar informações objetivas a respeito de intervalos de tempo, de modo a se reconstituir informações sobre o tempo e as vivências experimentadas no intervalo entre a revelação e o momento do atendimento. As entrevistas foram conduzidas pelo técnico da instituição previamente treinado e preparado para este fim. As pesquisadoras apenas interferiam, modificando uma pergunta a fim de torná-la mais compreensiva para os membros da família. Em $70 \%$ das entrevistas, a mãe foi figura constante. Estiveram presentes nas entrevistas: 7 mães, 3 pais, 9 vítimas, 1 avó, e outras pessoas como irmãos e 
irmãs. As entrevistas foram gravadas em áudio e depois transcritas.

Todas as famílias, por meio de seus responsáveis, assinaram o Termo de Consentimento Livre e Esclarecido. Os cuidados éticos referentes à conduta ética na pesquisa com seres humanos foram considerados, e o projeto de pesquisa foi aprovado pelo Comitê de Ética da Plataforma Brasil, com o parecer número 223032.

A análise dos dados se deu de forma quantitativa na apresentação dos resultados, utilizando a estatística descritiva. Apresentou-se a discussão de forma qualitativa, utilizando a hermenêutica dialética para a interpretação e compreensão dos dados das entrevistas.

\section{Resultados}

Os resultados tratados a partir da estatística descritiva são apresentados em duas categorias, sendo o primeiro referente à configuração familiar e o abuso sexual (tabela 1); e o segundo, ao tempo entre a revelação do abuso sexual e o atendimento (tabela 2). As categorias foram organizadas a partir das narrativas e percepções dos participantes reveladas na entrevista, consideradas relevantes na composição da violência vivida, permitindo conhecer a realidade dessas famílias e sua caracterização. A análise das entrevistas apresenta possibilidades de se conhecer a dinâmica de relações e eventos que se passam com a família durante o intervalo entre a revelação e o atendimento.

\section{A configuração familiar e o abuso sexual}

a) A configuração familiar caracteriza-se pela presença das mães em sete famílias dentre as nove aqui apresentadas. A figura paterna é observada em três famílias e verifica-se a presença de outros membros da família extensa em três famílias, como avó, tia/o, primos. b) Seis famílias estão em situação de abuso sexual intrafamiliar e dentre as 13 vítimas, 11 são meninas. A idade média dessas vítimas é de oito anos e oito meses. As vítimas foram abusadas em maior número por adultos (seis): pai, padrasto, adulto conhecido da família, tio, motorista de van. c) Os abusos cometidos por adolescentes (três) foram perpetrados por primos e irmão. d) Em seis entrevistas a mãe estava presente. E em seis outras entrevistas, a vítima também esteve presente. e) Em cinco famílias, somente o núcleo familiar coabitava. Em outras quatro famílias, havia a presença de outros familiares coabitando, sendo que dessas famílias, em quatro delas, o abusador morava na casa.

\section{O tempo entre a revelação do abuso sexual e o atendimento}

O tempo mínimo da ocorrência do abuso sexual, em relação ao momento da entrevista foi de sete meses; tempo médio foi de 27 meses; tempo máximo foi de sete anos; b) O tempo mínimo entre a ocorrência do abuso e a revelação foi de dois meses; o tempo médio foi de 13 meses; e o tempo máximo foi de 16 meses; c) O intervalo de tempo da revelação à denúncia foi de sete meses; d) $\mathrm{O}$ intervalo de tempo ocorrido entre a denúncia e o encaminhamento à instituição foi de três meses; e) O tempo ocorrido entre o encaminhamento e o atendimento foi de dois meses; f) Grande número das denúncias foi realizado por membros da família: mãe, irmã, irmão, avó e a própria vítima; g) As crianças têm maior facilidade que os adolescentes de revelar o abuso sexual às suas mães; h) As instituições que receberam as denúncias foram: CT (um), escola (um), Creas (um), DPCA (um), DP (um). Nos demais casos, as denúncias foram de origem intrafamiliar.

\section{Resultados qualitativos}

As categorias que organizam os resultados foram balizadoras para a descrição das informações relativas ao tempo e a trajetória das famílias. Nossa hipótese é que a família necessita de um tempo 
Tabela 1

Configuração familiar e abuso sexual

\begin{tabular}{|c|c|c|c|}
\hline $\begin{array}{l}\text { Sexo, Idade e Escolaridade da } \\
\text { Vítima. }\end{array}$ & Agressor & $\begin{array}{l}\text { Quem participou da } \\
\text { entrevista }\end{array}$ & Membros da família \\
\hline $\begin{array}{l}\text { Família } 1 \\
\text { Masc., } 8 \text { anos, } 1^{\text {a }} \text { s. EF }\end{array}$ & Primo de 15 anos & Mãe e a vítima & $\begin{array}{l}\text { Mãe, vítima, primo ofensor, tia } \\
\text { materna, avos maternos, }\end{array}$ \\
\hline $\begin{array}{l}\text { Família } 2 \\
\text { Fem., } 8 \text { anos: } 2^{\text {a }} \text { s; Fem. } 9 \text { anos: } \\
3 \text { s; Fem., } 10 \text { anos: } 4 \text { EF }\end{array}$ & Irmão de 15 anos & Pai & Pai, as 3 filhas e o filho ofensor \\
\hline $\begin{array}{l}\text { Família } 3 \\
\text { Fem., } 13 \text { anos, } 6^{\text {a }} \text { s. EF }\end{array}$ & Namorado de 24 anos & Adolescente & $\begin{array}{l}\text { Mãe, } 4 \text { irmãs, } 2 \text { irmãos, } 1 \\
\text { sobrinho de } 1 \text { ano }\end{array}$ \\
\hline $\begin{array}{l}\text { Família } 4 \\
\text { Fem., } 11 \text { anos, } 5^{\text {a }} \text { s. EF }\end{array}$ & Pai & Mãe ,vítima, duas filhas & mãe e 3 filhas \\
\hline $\begin{array}{l}\text { Família } 5 \\
\text { Fem., } 8 \text { anos, } 1^{\mathrm{a}} \text { s. EF }\end{array}$ & Padrasto & $\begin{array}{l}\text { Mãe, vítima e } 1 \text { filho de } \\
1 \text { ano }\end{array}$ & Mãe, filha e filho \\
\hline $\begin{array}{l}\text { Família } 6 \\
\text { Fem., } 16 \text { anos, } 5^{\mathrm{a}} \text { s. EF }\end{array}$ & Tio de 40 anos & Mãe, pai, filha (vítima) & $\begin{array}{l}\text { Mãe, pai, dois filhos de } 17 \text { e } 18 \\
\text { anos, filha de } 16 \text { anos }\end{array}$ \\
\hline $\begin{array}{l}\text { Família } 7 \\
\text { Fem., } 2 / 5 \text { anos. } 2 \text { anos não estuda } \\
\text { e } 5 \text { anos pré- escola } \\
\text { Masc., } 8 \text { anos, } 2^{\mathrm{a}} \text { s EF }\end{array}$ & Primo 15 anos & $\begin{array}{l}\text { Avó, } 2 \text { netas, } 1 \text { neto } \\
\text { (os três vítimas) }\end{array}$ & $\begin{array}{l}\text { Avó, } 2 \text { filhas, } 1 \text { nora, } 2 \text { netas, } 3 \\
\text { netos }\end{array}$ \\
\hline $\begin{array}{l}\text { Família } 8 \\
\text { Fem., } 13 \text { anos, } 6^{\text {a }} \text { s. EF }\end{array}$ & $\begin{array}{l}\text { Rapaz de } 24 \text { anos, tra- } \\
\text { ficante. }\end{array}$ & $\begin{array}{l}\text { Mãe, pai e a filha } \\
\text { (Vítima) }\end{array}$ & Mãe, pai, 2 filhos, 1 filha \\
\hline $\begin{array}{l}\text { Família } 9 \\
\text { Fem., } 4 \text { anos, pré escola }\end{array}$ & Motorista de van escolar & Mãe & Mãe, avó, 2 filhas e 3 filhos \\
\hline
\end{tabular}

Note. Masc.: masculino; Fem.: feminino; EF: Ensino Fundamental.

Tabela 2

O tempo entre a revelação do abuso sexual e o atendimento

\begin{tabular}{|c|c|c|c|c|c|}
\hline $\begin{array}{l}\text { Quem denunciou para } \\
\text { qual instituição }\end{array}$ & $\begin{array}{c}\text { Quando ocorreu o } \\
\text { abuso sexual }\end{array}$ & $\begin{array}{c}\text { Quando ocorreu a } \\
\text { revelação }\end{array}$ & $\begin{array}{c}\text { Quando foi feita a } \\
\text { denúncia }\end{array}$ & $\begin{array}{c}\text { Data do encaminha- } \\
\text { Mento }\end{array}$ & Data do acolhimento \\
\hline Família 1- & $\mathrm{AGO} / 2012$ & NOV/ 2012 & DEZ/2012 & JAN/2013 & FEV/ 2013 \\
\hline $\begin{array}{l}\text { Mãe da vitima ao } \\
\text { Conselho Tutelar }\end{array}$ & $\begin{array}{l}\text { Cerca de } 1 \text { ano } \\
\text { antes }\end{array}$ & $\begin{array}{l}4 \mathrm{~ms} \text { depois do } \\
\text { início abuso }\end{array}$ & $\begin{array}{l}1 \mathrm{~m} \text { depois da } \\
\text { revelação }\end{array}$ & $\begin{array}{l}1 \mathrm{~m} . \text { depois da } \\
\text { denúncia }\end{array}$ & $\begin{array}{l}1 \mathrm{~m} \text { depois do } \\
\text { encaminhamento }\end{array}$ \\
\hline $\begin{array}{l}\text { Família 2- } \\
\text { Vizinha }\end{array}$ & $\begin{array}{l}\text { FEV/2011 cerca } \\
\text { de } 2 \text { antes }\end{array}$ & Pai nega o abuso & $\begin{array}{l}\mathrm{DEZ} / 201222 \\
\text { ms depois do } \\
\text { abuso }\end{array}$ & $\begin{array}{l}\text { DEZ/ } 2012 \text { Mesmo } \\
\text { mês da denúncia }\end{array}$ & $\begin{array}{l}\mathrm{FEV} / 2013 \\
2 \mathrm{~ms} \text { depois do } \\
\text { encaminhamento }\end{array}$ \\
\hline $\begin{array}{l}\text { Família 3- } \\
\text { Ex-namorada do ofen- } \\
\text { sor à escola da vítima. }\end{array}$ & $\begin{array}{l}2^{\circ} \text { sem. de } 2012 \\
\text { Cerca de } 2 \text { anos } \\
\text { antes }\end{array}$ & $\begin{array}{l}\mathrm{FEV} / 2012 \\
6 \mathrm{~ms} \text { depois do } \\
\text { início abuso }\end{array}$ & $\begin{array}{l}\text { NOV/ } 20127 \mathrm{~ms} \\
\text { depois da reve- } \\
\text { lação }\end{array}$ & $\begin{array}{l}\mathrm{AGO} / 2012 \\
\text { Encaminha- } \\
\text { mento anterior à } \\
\text { denúncia }\end{array}$ & $\begin{array}{l}\text { FEV/ } 2013 \\
8 \mathrm{~ms} \text { depois do } \\
\text { encaminhamento }\end{array}$ \\
\hline $\begin{array}{l}\text { Família 4- } \\
\text { Irmã mais nova ao } \\
\text { Creas }\end{array}$ & $\begin{array}{l}\text { Desde os } 6 \text { anos. } \\
\text { Cerca de } 5 \text { anos } \\
\text { antes }\end{array}$ & $\begin{array}{l}\mathrm{FEV} / 2012 \\
5 \text { anos depois } \\
\text { do inicio do } \\
\text { abuso }\end{array}$ & $\begin{array}{l}\text { Há } 2 \text { semanas } \\
\text { Mesmo mês da } \\
\text { revelação }\end{array}$ & $\begin{array}{l}\mathrm{FEV} / 2013 \\
\text { Mesmo mês da } \\
\text { denúncia }\end{array}$ & $\begin{array}{l}\text { FEV/ } 2013 \\
\text { Mesmo mês do } \\
\text { encaminhamento }\end{array}$ \\
\hline
\end{tabular}




\begin{tabular}{|c|c|c|c|c|c|}
\hline $\begin{array}{c}\text { Quem denunciou para } \\
\text { qual instituição }\end{array}$ & $\begin{array}{c}\text { Quando ocorreu o } \\
\text { abuso sexual }\end{array}$ & $\begin{array}{l}\text { Quando ocorreu a } \\
\text { revelação }\end{array}$ & $\begin{array}{c}\text { Quando foi feita a } \\
\text { denúncia }\end{array}$ & $\begin{array}{c}\text { Data do encaminha- } \\
\text { Mento }\end{array}$ & Data do acolhimento \\
\hline $\begin{array}{l}\text { Família 5- } \\
\text { Filha mais velha } \\
\text { à Del. Proteção a } \\
\text { Criança e Adolesc. }\end{array}$ & $\begin{array}{l}1^{\circ} \text { sem. } \\
2012 \text { cerca de } 3 \\
\text { anos antes }\end{array}$ & $\begin{array}{l}2^{\circ} \mathrm{sem} .2010 \\
6 \mathrm{~ms} \text { depois do } \\
\text { início do abuso }\end{array}$ & $\begin{array}{l}2^{\circ} \text { sem. } 2011 \\
12 \text { ms depois da } \\
\text { revelação }\end{array}$ & $\begin{array}{l}\mathrm{FEV} / 2013 \\
20 \mathrm{~ms} \text { depois da } \\
\text { denúncia }\end{array}$ & $\begin{array}{l}\text { FEV/ } 2013 \\
\text { Mesmo mês do } \\
\text { encaminhamento }\end{array}$ \\
\hline $\begin{array}{l}\text { Família } 6 \\
\text { Irmão seguiu a irmã e } \\
\text { descobriu }\end{array}$ & $\begin{array}{l}1^{\circ} \text { sem. de } 2009 \\
\text { Cerca de } 4 \text { anos } \\
\text { antes }\end{array}$ & $\begin{array}{l}1^{\mathrm{o}} \mathrm{sem} .2010 \\
1 \text { ano depois do } \\
\text { início do abuso }\end{array}$ & $\begin{array}{l}1^{\circ} \text { sem. } 2012 \\
24 \text { ms depois da } \\
\text { revelação }\end{array}$ & $\begin{array}{l}\mathrm{DEZ} / 2012 \\
6 \mathrm{~ms} \text { depois da } \\
\text { denúncia }\end{array}$ & $\begin{array}{l}\text { FEV/ } 2013 \\
1 \mathrm{~m} \text { depois do enca- } \\
\text { minhamento }\end{array}$ \\
\hline $\begin{array}{l}\text { Família } 7 \text { - } \\
\text { Netos contaram para } \\
\text { avó }\end{array}$ & $\begin{array}{l}1^{\mathrm{o}} \text { sem. de } 2011 \\
\text { Cerca de } 2 \text { anos } \\
\text { antes }\end{array}$ & $\begin{array}{l}\mathrm{FEV} / 2012 \\
1 \text { ano depois do } \\
\text { início do abuso }\end{array}$ & $\begin{array}{l}\mathrm{DEV} / 2012 \\
\text { Mesmo mês da } \\
\text { revelação }\end{array}$ & $\begin{array}{l}\text { FEV/ } 2013 \\
3 \text { ms depois da } \\
\text { denúncia }\end{array}$ & $\begin{array}{l}\text { FEV/ } 2013 \\
\text { Mesmo mês do } \\
\text { encaminhamento }\end{array}$ \\
\hline $\begin{array}{l}\text { Família 8- } \\
\text { A filha contou para a } \\
\text { mãe, depois de muita } \\
\text { pressão. }\end{array}$ & $\begin{array}{l}\mathrm{FEV} / 2012 \\
\text { Cerca de } 1 \text { ano } \\
\text { antes }\end{array}$ & $\begin{array}{l}\mathrm{AGO} / 2012 \\
6 \mathrm{~ms} \text { depois do } \\
\text { início do abuso }\end{array}$ & $\begin{array}{l}\mathrm{NOV} / 2012 \\
3 \mathrm{~ms} \text { depois da } \\
\text { revelação }\end{array}$ & $\begin{array}{l}\text { NOV/ } 2012 \\
\text { Mesmo mês da } \\
\text { revelação }\end{array}$ & $\begin{array}{l}\mathrm{MAR} / 2013 \\
4 \mathrm{~ms} \text { depois do } \\
\text { encaminhamento }\end{array}$ \\
\hline $\begin{array}{l}\text { Família } 9 \text { - } \\
\text { Avó à Delegacia }\end{array}$ & $\begin{array}{l}\mathrm{AGO} / 2012 \\
\text { cerca de } 1 \text { ano } \\
\text { antes }\end{array}$ & $\begin{array}{l}\text { OUT/ } 2012 \\
2 \mathrm{~ms} \text { depois do } \\
\text { início do abuso }\end{array}$ & $\begin{array}{l}\mathrm{NOV} / 2012 \\
1 \mathrm{~m} \text { depois da } \\
\text { revelação }\end{array}$ & $\begin{array}{l}\mathrm{DEZ} / 2012 \\
1 \mathrm{~m} \text { depois da reve- } \\
\text { lação }\end{array}$ & $\begin{array}{l}\text { MAR/ } 2013 \\
3 \text { ms depois do } \\
\text { encaminhamento }\end{array}$ \\
\hline
\end{tabular}

Note. AGO: Agosto; FE: Fevereiro; NOV: Novembro; OUT: Outubro; DEZ: Dezembro; $2^{\circ}$ sem: segundo semestre; Ms: meses.

organizador de suas primeiras emoções, sofrimentos e perturbações. Esse tempo que nem sempre tem medida é vivido na interação com a família e sugere a elaboração e assimilação da violência, que impulsiona a família para uma tomada de posição fora de seus muros, quer seja realizando a notificação, buscando algum tipo de ajuda ou mesmo fazendo sua própria justiça. Fez-se importante conhecer e identificar uma parcela relevante dos conflitos vividos neste ínterim, ameaças de outros eventos em curso, aspectos psicológicos, emocionais e comportamentais advindos com a revelação do abuso sexual.

Opta-se, nesse ponto, por se acrescentar algumas informações, presentes nas entrevistas que identificam muitos conflitos familiares e que podem servir de base para melhor compreensão do que se passa no intervalo de tempo entre a revelação e a chegada a uma instituição: Família 1, informou, por meio da mãe da vítima, que sua maior dificuldade não é a questão do abuso sexual, mas a relação conflitiva que existe entre ela e sua própria mãe. A avó materna mora com a família e exerce função fundamental de ajuda. Quem abusou da vítima foi seu primo, também neto dessa avó. "Não sei. Aí depois ela fica falando pra minha irmã não [...] Sara é muito boa pra mim eu saio quando chego tem comida pronta, faz sabão faz tudo pra mim [...], mas depois ela começa a falar coisa e me xingar e xingar e xingar e bater no Pedro, sem a gente ter feito nada". No decorrer da entrevista, a mãe da vítima acaba por denunciar que também foi abusada sexualmente pelo companheiro de sua própria mãe. Este abuso nunca havia antes sido revelado.

O pai entrevistado (Família 2) cria os filhos sozinho. Disse ainda estar triste porque o filho (ofensor sexual) desapontou a esperança dele de que seria alguém na vida, e agora está detido por conta de furtos e "outras coisas":

Eu não fiz nada com meu filho, porque eu não sei, porque eu nunca deixei as meninas sozinha com ele. Mas, esse negócio de deixar meninas e meninos juntos não dá certo. Mas, eu nunca vi. [...] Eu penso o seguinte: o jeito que tá... é... como 
pode se dizer... como na televisão o ato sexual aparece mais toda hora, um moleque de 10 anos vê isso toda hora em filme desenho em tudo o que ta passando. Então vai querer fazer a mesma coisa. E aí pode ter acontecido alguma coisa [...].

A adolescente (Família 3) foi sozinha à entrevista, pois sua mãe ligou dizendo que não iria acompanhá-la e não queria mais cuidar dessa filha. Ambas têm uma relação bastante conturbada. A adolescente fugia da escola para ter relações sexuais com o namorado. "Tem muito bate boca entre nós duas [...]". A mãe da família 4 informou que o abusador, pai da adolescente, está preso. Isto se constitui em um fato "terrível", pois ela está sozinha, e não acredita que a violência tenha acontecido. "Melhorou que elas estão mais calmas. Eu também. A gente tá mais... mais tipo assim na felicidade, sabe? Aquela alegria assim. Parece que saiu foi um... uma coisa assim que parece que tava levando a gente assim lá pra baixo, sabe [...] mas é muito difícil ficar sem meu marido [...]".

"O que sobrou do horror da minha vida". Esta foi a fala da mãe da Família 5, junto à outras informações acerca do histórico de internações psiquiátricas, de drogas, de roubo na família, demonstrando claramente a dificuldade em associar todos esses eventos. Já a mãe da Família 6 nos traz uma situação que é a grande quantidade de pessoas que dividem um mesmo lote, o qual comporta vários barracos, mas com grande proximidade física entre seus moradores. "Eu tinha o maior medo de que a minha filha fosse ameaçada lá fora... ela tava sendo ameaçada, dentro de casa, pelo meu cunhado [...]". A família 7 é liderada pela avó, de 67 anos. $\mathrm{Na}$ casa vivem várias pessoas de diferentes idades. Os filhos adultos não conseguiram sair da casa até hoje, e não conseguem ter autonomia. São cinco netos a residirem na casa, sendo que o neto de 15 anos abusou das crianças de 2, 5 e 8 anos de idade. O outro neto de 17 anos já cometeu homicídio, e está morando na casa para se esconder e não ser morto. "Eu fiquei muito abalada na época, eu senti muita raiva, eu bati nele. Hoje eu sinto raiva, mas já não é do jeito como estava. Ele debochava dos meninos, mas ele parou, porque toda vez que ele começava a debochar eu brigava com ele [...]". A mãe da família 8 suspeita que a filha possa ter tido relações sexuais, mas tem dúvidas se foi com o consentimento dela ou por imposição do rapaz. Desde pequena ela foi mais apegada ao pai. Com relação à família 9 , a mãe veio sozinha à entrevista. A filha ia para a escola de van e o motorista abusava dela durante o trajeto. Nessa família são cinco crianças em casa e muitos namorados dessa mãe. A mãe é extremamente violenta com as crianças.

\section{Discussão}

Através desses pequenos extratos de conflitos presentes nas famílias, reconhece-se a preexistência de uma situação de problemas graves antes do momento da revelação do abuso sexual. São conflitos que podem ser acirrados com a revelação da violência. Nota-se o envolvimento de vários membros da família nuclear, e extensa, nessa rede de ambiguidades. Considera-se a hipótese de que o período de tempo entre a revelação e o atendimento seja vivido entre angústias e preocupações que unem todos os membros da família em uma demanda por assimilarem a violência como violência, já que muitas vezes é a primeira oportunidade que têm para assim o fazer. O que está se advogando aqui é a compreensão de que o período de tempo é longo, e talvez seja o necessário e indicado para que a família consiga acolher o novo problema surgido com a revelação, junto aos antigos problemas que podem ser acirrados nesse momento.

\section{A configuração familiar e o abuso sexual: clientela do Creas semelhante a outros estudos}

Em nove famílias entrevistadas, seis estão em situação de abuso sexual intrafamiliar e dentre as 13 
vítimas, 11 são meninas. Publicações mostram que a maioria dos casos de abuso sexual é perpetrada por membros da família da vítima, ou por pessoa próxima, que estabelece com a vítima, uma relação de confiança (Baia et al., 2015; Cardin, Mochi \& Bannach, 2011). Autores internacionais, Frías e Erviti (2014) e Sigurdardottir, Halldorrsdottir e Bender (2014) destacam e diferenciam características de vítimas do sexo masculino e feminino: enquanto que para as meninas, as chances de exposição à vitimização sexual aumentam com a chegada da puberdade, para os meninos aparentemente é o inverso. Diversos estudos nacionais (Baia et al., 2015; Martins \& Jorge, 2010; Modelli, Galvão \& Pratesi, 2012) apontam que a predominância dos meninos vitimizados sexualmente encontra-se nas faixas etárias mais novas.

Embora todos os membros da família fossem convocados a participar da entrevista de acolhimento no Creas, em sete, das nove entrevistas, houve a presença da mãe e a criança ou adolescente vítima e mais alguns membros da família. Em apenas uma situação, a adolescente vítima compareceu sozinha; e em outro acolhimento quem compareceu foi o pai. Em nenhuma entrevista observou-se a participação de todos os membros da família. A ausência de outros membros da família apresenta-nos a dificuldade de se dar uma abordagem familiar à situação de abuso sexual. No entanto, fica evidente que as mães se apresentam como a figura protetiva que comparece à instituição e inicia o processo de atendimento psicológico à vítima. Deve haver, portanto, um reconhecimento necessário para a mudança de pensamento relativo à conduta materna. Durante um período anterior à revelação a mãe foi, por muito tempo considerada conivente com o abuso sexual (Costa et al., 2007; Santos,\& Dell'Aglio, 2008).

A maioria das vítimas está em uma escolaridade compatível com sua idade e coincidente com as estatísticas já disponíveis (Habigzang \& Koller, 2011; Costa et al., 2013; Marra, 2015). Nesse grupo as vítimas foram abusadas, em maior número, por adultos do que por adolescentes. Têm-se três abusadores adolescentes, dois abusadores de 24 anos, dois abusadores com função paterna, um tio e um motorista de van escolar. Esse resultado, embora esteja em consonância com outros números já publicados (Costa et al., 2007) choca-se com uma estatística disponível no site da Vara da Infância e Juventude do Distrito Federal (VIJ, 2010), que identifica, a partir de 2010, uma tendência ao aumento relevante dos abusos sexuais cometidos por adolescentes em comparação com o número de abusos cometidos por adultos.

A presença de membros da família extensa na configuração familiar surge como uma característica do contexto da cidade na qual a pesquisa ocorre, uma vez que subsiste uma política de assentamento em que várias famílias dividem lotes de terra doados pelo governo (Penso, Costa, Conceição \& Carreteiro, 2013). Esse aspecto é sobremaneira relevante, pois é considerado bastante facilitador do abuso sexual, já que os parentes acumulam funções de cuidados com as crianças, especialmente os adolescentes. Há ainda a facilitação de grande proximidade física entre adultos, crianças e adolescentes, além da presença de vários familiares morando na casa, possivelmente outros membros transitando também. Outro ponto a se considerar é a presença de duas avós morando no lar, sendo uma responsável pelas crianças e outra pelo lar, junta à mãe. Esse aspecto merece atenção, pois a presença da avó pode, quando ela é responsável pela guarda ou cuidado de outros netos adolescentes que vivem com ela, ser determinante do abuso sexual, como é o caso da Família 7. (tabela 1).

A amostra que se deu no decorrer de apenas dois meses de acesso ao campo da pesquisa apresentou nove famílias e 13 vítimas com uma particularidade interessante, que é a presença de crianças vítimas na entrevista de acolhimento. Trata-se da disponibilidade das famílias de engajarem a vítima no atendimento desde o seu início. Todos esses aspectos configuram uma situação que traz 
vulnerabilidades para o cuidado e a proteção, que devem recair sobre crianças e adolescentes. Esses resultados apresentam coincidências com estudos apontados em Costa et al. (2007), Santos e Dell'Aglio (2010) e Habigzang e Koller (2011).

Quando observada a totalidade dos sintomas e comportamentos vividos por essas famílias, nesta pequena amostra, pode-se verificar que o impacto da violência sexual está correspondente a três conjuntos de fatores: intrínsecos à criança e/ou adolescente, relacionados às crenças, percepções e narrativas construídas ao longo de suas experiências, como se sente culpada e a não identificação com seus pares, etc. Os fatores extrínsecos relacionados à sua rede de apoio social e afetiva, que dizem respeito aos fatores de risco e proteção, que são as pessoas significativas que compõem a vida da vítima. E os fatores relacionados à violência sexual propriamente dita, que estão impactados no seu desenvolvimento (Murray, Nguyen \& Cohen, 2014; Habigzang \& Koller, 2011). São fatores ou circunstâncias significativas que favorecem a criança tornar-se vítima ou agente de violência em tempo presente. Influenciam na determinação de dados de vulnerabilidade, dados que se mostram coincidentes com os apresentados nos resultados anteriormente descritos nas várias situações.

\section{O tempo entre a revelação do abuso sexual e o atendimento: muito tempo sem intervenção}

O aparecimento de sentimentos, percepções quando da revelação impulsiona uma diversidade de posturas e comportamentos em cada família, mobilizando-as para ações como: silenciam e vivem na angústia paralisante, outros querem justiça, outros são displicentes deixando a criança e/ou adolescente conviver por mais um longo tempo com o ofensor, outros buscam serviços de proteção e informações nos órgãos especializados, etc. A questão do tempo é vivido e interpretado pelas famílias de modo diferente, segundo suas condições.
Quando a revelação se faz em um contínuo com o atendimento, fortalece as ações para um cuidado vigilante, impedindo que as crianças sofram novos abusos de pessoas que os circulam. Possibilita ainda a descoberta de outras violências que a família vive, além de impedir situações em que a vítima é exposta a situações constrangedoras e de mais sofrimentos. Costa e Penso (2010) afirmam que as intervenções psicossociais são possibilidades de promover um espaço com poder transformador e que elas não necessitam das características demandadas por um contexto clínico tradicional.

A revelação do abuso sexual traz tantos impactos e transtornos à família, sendo vistas como tabus sociais, provocando mudanças na organização, que mesmo não sendo confortável, estava funcionando. A partir do momento em que os conflitos estão ressaltados podem ocasionar rompimentos de vínculos, desconfiança e inseguranças. O esforço subsequente para buscar estratégias viáveis e restauradoras pode não ser eficaz e a família se desorganiza. Dell'Aglio (2010) e Martins e Jorge (2010) falam da importância do apoio familiar e da importância do atendimento logo após a revelação para a redução de sintomas para a vítima de abuso.

As informações da tabela 2, que discute a categoria: tempo entre a revelação do abuso sexual e o atendimento oferecem um quadro mais específico para se compreender, o que ocorre com a família desde o momento que a vítima expõe o abuso sexual para os demais membros da família, até o momento que se apresentam à instituição. Esses tempos podem ser assim percebidos: as crianças e adolescentes desta amostra viveram o abuso sexual em uma média de 27 meses atrás. O tempo médio entre a ocorrência do abuso e a revelação foi de 13 meses. O intervalo de tempo da revelação à denúncia foi de sete meses, e o da denúncia ao encaminhamento a uma instituição foi de três meses. E, finalmente, o tempo entre o encaminhamento ao atendimento foi de dois meses.

Excetuando uma vizinha que ficou responsável pela denúncia (Família 2), e uma ex-namorada 
(Família 3), todas as outras denúncias foram relatadas por membros da família: mãe, irmãs, irmãos e avó. A literatura discute a condição controversa que a família possui na proteção das vítimas, porém aqui se encontra um dado que recoloca a família em seu poder protetivo, quando são os parentes próximos os responsáveis pela interrupção da violência (Santos \& Dell'Aglio, 2008). Além disso, nota-se que as denúncias são feitas de maneira correta, uma vez que as famílias têm recorrido às instituições apropriadas para tal, como o Conselho Tutelar - CT-, o Centro de Referência Especializada em Assistência Social, a Delegacia de Proteção à Criança e ao Adolescente - DPCA- e as Delegacias de Polícia - DPs-. Este resultado coincide com Habigzang e Koller (2011).

Há ainda que se destacar a denúncia realizada junto à escola, no caso da Família 3. Essa informação é importante, pois cada vez mais a escola é considerada um contexto de proteção à situação de abuso sexual. Espindola e Batista (2013) apontam a escola como a terceira instituição mais procurada pelas vítimas para denúncia de abuso sexual, vindo apenas após os membros da família. Pode-se inferir que esta posição de referência de proteção se deve à propaganda desencadeada pela política governamental de promoção e garantia de direitos. As devidas orientações direcionadas à comunidade escolar, que vem sendo estampados ao longo do tempo, tem promovido uma discussão mais aberta na sociedade sobre a violência sexual (Brasil, 1990/2010; Portaria n. ${ }^{\circ}$ 1.968, 2001; Lei n. ${ }^{\circ}$ 12.845, 2013; Ministério da Justiça, 2002; Portaria n. ${ }^{\circ}$ 528, 2013).

O tempo médio da ocorrência do abuso sexual foi de 27 meses e o tempo médio do momento da revelação ao atendimento foi de 13 meses. Essa constatação coincide com a literatura (Habigzang \& Koller, 2011; Santos \& Dell'Aglio, 2010) e revela que há um tempo relativamente grande, quando se trata de interromper a violência e restabelecer a proteção. Ao cenário dos possíveis danos causados pela violência, acrescenta-se o tempo médio de sete meses transcorrido entre a revelação feita pela vítima e a denúncia e/ou notificação. Além de ser mais um tempo acrescido à demora já existente, esse dado revela as dificuldades que a família experimenta ao tornar público o acontecimento, e assim, se colocar à disposição da responsabilização da sociedade. Sabe-se que muitas famílias, efetuam nesse momento a tentativa de interrupção da violência por meio da justiça particular, fazendo modificações na organização familiar ou responsabilizando o abusador, quando ele é um membro intrafamiliar (Costa et al., 2013). A questão é que essas providências visam mudanças que, de fato, não interrompem a violência com efetividade. As famílias 2 e 3 não conseguiram romper com o segredo e buscar atendimento. Foi necessária a intervenção de uma pessoa da rede familiar para se efetuar a denúncia. Este fato corrobora mais uma vez a importância da divulgação midiática dos serviços e programas de atenção à violência; e da participação e responsabilidade da sociedade, no intuito de minimizar os efeitos das situações de violência por abuso sexual.

Um aspecto importante da tabela 2 é que as crianças têm maior facilidade que os adolescentes de revelar o abuso as suas mães e/ou avós (famílias 1, 4, 7, 9). Pode-se pensar que as crianças têm menor clareza das ocorrências que a revelação vai desencadear? As adolescentes parecem ter certo entendimento do significado do abuso, das consequências da revelação e do sofrimento que será gerado em suas mães, e esses elementos podem impedi-las de se exporem. A percepção que a criança e ou adolescente tem de sua mãe ou da pessoa a quem vai contar sobre o abuso, incluindo o contexto familiar, influencia sua disponibilidade para revelar ou não o que lhe aconteceu (Plummer, 2006).

Nesta amostra, nas famílias 1, 4, 6 e 8, as filhas ou o filho, contaram sobre o abuso à mãe; e nas famílias 7 e 9 as crianças contaram à avó. Constata-se certa acessibilidade das mães e/ou avós para ouvirem as histórias das filhas e lhes 
dar crédito, ainda que em alguns casos, do acolhimento à revelação demore, retardando assim o início de um processo de responsabilização do ofensor. Alguns autores falam ainda da questão da familiaridade com o abusador ou a severidade do abuso ou, ainda, quando o ato é praticado por alguém com quem a vítima mantém laços afetivos significativos, como indicadores de interferência no processo de revelação (Pelisoli, Pires, Almeida \& Dell'Aglio, 2010). Justificadas por estas questões, muitas famílias não conseguem romper com o segredo. Embora a criança tenha conseguido fazer a revelação, a família não avança no processo de responsabilização do agressor. Pode-se certificar este fato nas informações dadas pelas famílias 2, 4, 5. Como nos aponta Jensen et al. (2005), as reações dos adultos são como indicadores para o que podem ou não falar. A criança só conta o abuso sofrido a uma pessoa que confia quando esta demonstra estar preparada psicologicamente para escutar, sem dar sinais de desespero, repúdio ou condenação moral.

Observa-se nas famílias 4, 5 e 6 que os abusos sexuais iniciaram com as adolescentes ainda crianças, demarcando um longo tempo entre o abuso e a revelação. A família que busca denunciar o abuso sexual imediatamente ao saber dos fatos tem acesso mais rápido ao atendimento. Pode-se ainda observar, que o tempo médio entre o encaminhamento e o atendimento de fato é de 5 meses. Isto significa que as unidades de atendimento têm conseguido iniciar suas intervenções em um tempo mais curto. Algumas famílias conseguem vivenciar o processo da denúncia ao atendimento em menos de um ano, como ocorreu com as famílias $1,2,4,7,8$ e 9 . Trata-se do efeito de uma maior conscientização das famílias em razão de acesso a mais informações sobre a significação do abuso sexual como violência?

Ainda com relação ao tempo médio entre o abuso e a revelação que foi de 27 meses, pode-se destacar que quase todas as famílias da amostra (2, $3,4,5,6,7)$ viveram um longo tempo em situação de abuso sexual e um longo tempo até a revelação, comprovando o que a literatura diz a esse respeito (Habigzang \& Koller, 2011). Este é o tempo que a genitora tem dispendido para compreender os sinais que a vítima vai oferecendo (Plummer, 2006). Nesta amostra os serviços especializados foram eficientes quando a família cumpriu seu papel de fazer a notificação após a revelação dentro do período de seis meses, como evidenciado pela literatura. Essa resposta mais rápida dos serviços merece um estudo mais aprofundado para compreensão de quais elementos favorecem essa prontidão. Observa-se que exceto em 3 famílias $(3,5,6)$, as demais tiveram uma sequência desejável em seus atendimentos na rede de proteção especializada, de tal forma que a denúncia seguiu um contínuo de atendimento sem interrupção. $\mathrm{O}$ tempo médio entre a denúncia e o encaminhamento para atendimento na instituição foi de três meses e o tempo médio entre o encaminhamento e a entrevista de acolhimento foi de dois meses, mostrando que os órgãos especializados tendem a cumprir seu papel cada vez mais de forma competente e dentro dos prazos desejados. Faz-se necessária pesquisa no sentido de compreender quais os aspectos que estão facilitando essa maior celeridade no oferecimento de atendimento. As famílias 2, 3, 5 e 6 suscitam reflexões acerca da descrença nos órgãos de proteção, bem como uma dificuldade em aceitar a presença da violência sofrida. Com a demora do tempo de revelação à denúncia, parecem ter se reorganizado e se estabelecido em uma dinâmica relacional desorganizada e confusa que as paralisa diante da situação.

Os dados aqui acumulados nos possibilitam responder às três questões do início do estudo: $\mathrm{O}$ que ocorre com a família e a vítima nesse intervalo de tempo? Pode-se constatar que a revelação do abuso sexual é recebida pela família como uma ameaça ao seu modus vivendi naquele momento, gerando reações paradoxais que incluem proteção e imobilidade. Ao mesmo tempo em que se configura como uma ameaça ao arranjo familiar 
organizado, a violência é também um pedido de socorro, tanto para a vítima como para a família. A insegurança e as desconfianças do relato, no primeiro momento, impedem uma aproximação necessária entre os familiares para a tomada de decisão de revelar e publicizar a situação. Entretanto, uma vez feita a revelação, parte da família caminha no sentido de estabelecer uma união em função do objetivo comum: a reorganização. $\mathrm{O}$ intervalo de tempo entre a revelação do abuso sexual e as providências para o atendimento parecem ser vividas em função de uma assimilação do ocorrido e uma reorganização familiar até mesmo física e/ou espacial.

Como a família, ainda sem ajuda de profissionais especialistas, prossegue em sua rotina de vida? Quando as famílias chegam ao atendimento apresentam-se impactadas pela revelação, confusas, distanciadas da situação, preocupadas com a nova realidade. Pode-se observar que a família aparentemente apresenta uma inércia em relação ao problema. Uma observação mais acurada oferece a oportunidade de uma interpretação favorável ao movimento de mudança da família. Há necessidade de um tempo de elaboração psíquica do conflito. O tempo necessário para a mudança é vivido em interação familiar.

Qual significado é dado pela família a esse período de tempo? É um período de espera, de busca de compreensão do que aconteceu e de prontidão para a tomada efetiva de ações. A mãe, responsável pelo cuidado da criança demora a desencadear a proteção, muitas vezes porque é ela também que terá que fazer opções de rompimentos afetivos. No entanto, é ela também a pessoa que terá que dar conta do acúmulo de ações decorrentes da revelação. O tempo é empregado em negociações subjetivas, íntimas e familiares, em uma preparação para o advento de uma exposição da intimidade que leva a todos para o âmbito da responsabilização jurídica.

\section{Considerações finais}

A realização deste estudo permitiu conhecer uma amostra representativa de crianças e adolescentes e suas famílias vítimas de abuso sexual, seus tempos e processos vividos entre o período da revelação ao atendimento. Certamente esse intervalo de tempo entre a revelação e o atendimento é o tempo em que a família vive grande desordem relacional, psicológica e espacial. Esse período traz muitas ansiedades e outras manifestações e/ou tomada de consciência da existência de competições e atritos entre membros da família, que são agregados à descoberta da violência sexual. Enquanto a revelação já ocorreu unicamente no âmbito familiar, observa-se um sentimento de isolamento para lidar com todas as alterações no sistema familiar que a revelação mobilizou. Soma-se a isso a dificuldade que as famílias possuem na mobilidade social para a conquista de mudanças, o medo, o sentimento de impunidade são fatores associados a essa inicial imobilidade. Os personagens participantes desse longo, sofrido e árduo processo envolve famílias fragilizadas por diversas questões intra e extrafamiliares, crianças e adolescentes amedrontados, profissionais muitas vezes inseguros e com poucos recursos para atenção e intervenção. O tema e a abordagem ainda envolvem tabus importantes e a desarticulação evidente dos serviços que prestam atendimento, ainda constitui uma dificuldade para as famílias. Elementos sociais e culturais ainda são considerados impeditivos para a revelação/notificação e as famílias se sentem oprimidas diante desta situação que as impulsionam a viver perdas de grandes dimensões para suas vidas. Estes sentimentos levam a família a um distanciamento e a uma busca resiliente de seus recursos para dar conta da grave repercussão, em relação ao funcionamento físico, psicológico e social, uma vez que a ocorrência se dá no espaço familiar, que a priori deveria se configurar como espaço de proteção. Todas as vivências daí decorrentes estão associadas à qualidade das relações desta família e a criança 
vai sempre colocar as reações do adulto como fonte de inspiração e referência para reconstruir suas relações posteriores à revelação.

E, finalmente, o limite do texto está na amostra pequena, mas que proporcionou condições de levantamento de hipóteses, que podem explicar qualitativamente o que se passa com a família durante o período de silenciamento, que antecede à revelação do abuso sexual. No entanto, essa amostra pequena se deu no decorrer de apenas dois meses de acesso ao campo da pesquisa. Além disso, a carência de estudos nacionais sobre a questão vivida pelas famílias nesta fase do processo também limitou a discussão dos achados e sua confrontação com outras pesquisas. Outros estudos comprovam a presença de fatores que favorecem os limites no avanço de pesquisas nessa área, como dificuldades tanto no relato como na escassez de serviços voltados a essa população e a dificuldade em lidar e controlar o sofrimento diante de casos de violência sexual.

\section{Referências}

Baia, P. A. D., Veloso, M. M. X., Habigzang, L. F., Dell'Aglio, D. D. \& Magalhães, C. M. C. (2015). Padrões de revelação e descoberta do abuso sexual de criança e adolescente. Revista de Psicologia, 24(1), 1-19. DOI: 0581.2015.37007

Brasil (2005). Política Nacional de Assistência Social. Norma Operacional Básica (NOB/SUAS). Brasília: Ministério do Desenvolvimento Social e Combate à Fome/Secretaria Nacional de Assistência Social.

Cardin, V. S. D., Mochi, T. F. G. \& Bannach, R. (2011). Do abuso sexual intrafamiliar: uma violação aos direitos da personalidade da criança e do adolescente. Revista Jurídica Cesumar, 11(2), 401-432.

Clark, C., Caldwel, T., Power, C. \& Stansfeld, S. A. (2010). Does the influence of childhood adversity on psychopathology persist across the lifecourse? A 45-year prospective epidemiologic study. Annals of Epidemiology, 20(5), 385-394.

Costa, L. F., Junqueira, E. L., Meneses, F. F. F. \& Stroher, L. M. (2013). As relações familiares do adolescente ofensor sexual. Psico USF, 18(1), 33-44.

Costa, L. F., Penso, M. A., Rufini, B. R., Mendes, J. A. A. \& Borba, N. F. F. (2007). Família e abuso sexual: silêncio e sofrimento entre a denúncia e a intervenção terapêutica. Arquivos Brasileiros de Psicologia, 59(2), 245-255.

Costa, L. F. \& Penso, M. A. (2010). A dimensão clínica das intervenções psicossociais com adolescentes e família. Em M. M. Marra \& L. F. Costa (eds.), Temas da clínica do adolescente e família, 201-214. São Paulo: Ágora.

Espindola, G. A. \& Batista, V. (2013). Abuso sexual infanto-juvenil: A Atuação do Programa Sentinela na Cidade de Blumenau/sc. Psicologia: Ciência \& Profissão, 33(3), 596-661.

Fórum Brasileiro de Segurança Pública (2013). $7^{\text {a }}$ edição do Anuário Brasileiro de Segurança Pública. Disponível em http://www.forumseguranca. org.br/files/files/destaques_anuario2013.pdf.

Frías, S. M. \& Erviti, J. (2014). Gendered experiences of sexual abuse of teenagers and Children in Mexico. Child Abuse \& Neglect, 38(4), 776787. DOI: $10.1016 /$ j.chiabu.2013.12.001

Furniss, T. (2002). Abuso sexual da criança: uma abordagem multidisciplinar, manejo, terapia e intervenção legal integrados. Porto Alegre: Artes Médicas.

Habigzang, L. F. \& Koller, S. H. (2011). Abuso sexual contra crianças e adolescentes: Aspectos conceituais e estudos recentes. Em L. F. Habigzang \& S. H. Koller (orgs.), Intervenção psicológica para crianças e adolescentes vitimas de violência sexual. Manual de capacitação (pp. 11-40). São Paulo: Casa do Psicólogo.

Hershkowitz, I., Lanes, O. \& Lamb, M. E. (2007). Exploring the disclosure of child sexual abuse with alleged victims and their parents. Child Abuse \& Neglect, 31(2), 111-123. 
Jensen, T. K., Gulbrandsen, W., Mossige, S., Reichelt, S. \& Tjersland, O. A. (2005). Reporting possible sexual abuse: a qualitative study on Children's perspective and the context for disclosure. Child, Abuse \& Neglect, 29(12), 1395-1413.

Lei 2.435, de 6 de julho de 2011 (2011, 6 julho). Altera a Lei no 8.742, de 7 de dezembro de 1993, que dispõe sobre a organização da Assistência Social. Diário Oficial da União.

Lei $n^{\circ} 12.845$, de $1^{\circ}$ de agosto de 2013 (2013, 1 agosto). Dispõe sobre o atendimento obrigatório e integral de pessoas em situação de violência sexual. Diário Oficial da União.

Lovett, B. B. (2004). Child sexual abuse disclosure: maternal response and other variables impacting the victim. Child and Adolescent Social Work Journal, 21(4), 355-371.

Marra, M. M. (2015). Do espaço privado para o público: construções narrativas com famílias em situação de abuso sexual (Doctoral Dissertation). Disponível em repositorio.unb.br/ handle/10482/19763

Marra, M. M. (2016). Conversas criativas e abuso sexual. Uma proposta para o atendimento psicossocial. São Paulo: Ágora.

Martins, C. B. G. \& Jorge, M. H. M. P. M. (2010). Abuso sexual na infância e adolescência: perfil das vítimas e agressores em município do sul do Brasil. Texto Contexto Enfermagem, 19(2), 246-255.

Modelli, M. E. S., Galvão, M. F. \& Pratesi, R. (2012). Child sexual abuse. Forensic Science International, 217(1-3), 1-4.

Murray, L. K., Nguyen, A. \& Cohen, J. A. (2014). Childsexual abuse. Child and Adolescent Psychiatric Clinics of North America, 23(2), 321337. DOI: 10.1016/j.chc.2014.01.003

Passarela, C. M., Mendes, D. D. \& Maril, J. J. (2010). Revisão sistemática para estudar a eficácia de terapia cognitivo-comportamental para crianças e adolescentes abusadas sexualmente com transtorno de estresse pós-traumático. Revista Psiquiatria Clínica, 37(2), 60-65.

Pelisoli, C., Pires, J. P. M., Almeida, M. E. \& Dell'Aglio, D. D. (2010). Violência sexual contra crianças e adolescentes: Dados de um serviço de referência. Temas em Psicologia, 18(1), 85-97.

Penso, M. A., Costa, L. F., Conceição, M. I. G. \& Carreteiro, T. C. O. (2013). As mães dos adolescentes que cometeram ato infracional social e de natureza sexual. Interacções, 9(25), 151-179.

Plummer, C. A. (2006). The Discovery process: what the mothers see and do in gaining awareness of the sexual abuse of their children. Child Abuse \& Neglect, 30(11), 1227-1237.

Portaria ${ }^{\mathrm{o}} 1.968$, de 25 de outubro de 2001 (2001, 25 de outubro). Dispõe sobre a comunicação, às autoridades competentes, de casos de suspeita ou de confirmação de maus-tratos contra crianças e adolescentes atendidos nas entidades do Sistema Único de Saúde. Diário Oficial da União.

Portaria $n^{\circ} 528$, de $1^{\circ}$ de abril de 2013 (2013, 1 de abril). Define regras para habilitação e funcionamento dos Serviços de Atenção Integral às Pessoas em Situação de Violência Sexual no âmbito do Sistema Único de Saúde (SUS). Diário Oficial da União.

Resolução n¹09, de 11 de Novembro de 2009 (2009, 25 de novembro). Aprova a Tipificação Nacional de Serviços Socioassistenciais. Diário Oficial da União ${ }^{\circ} 225$, seção 1 .

Santos, S. S. \& Dell' Aglio, D. D. (2010). Quando o silêncio é rompido: o processo de revelação e notificação de abuso sexual. Psicologia \& Sociedade, 22(2), 328-335.

Santos, S. S. \& Dell'Aglio, D. D (2008). Compreendendo as mães de crianças vítimas de abuso sexual: Ciclo de violência. Estudos de Psicologia, 25(4), 595-606.

Serafim, A. P., Saffi, F., Achá, M. F. F. \& Barros, D. M. (2011). Dados demográficos, psicológicos 
e comportamentais de crianças e adolescentes vítimas de abuso sexual. Revista de Psiquiatria Clínica, 38(4), 143-147.

Sigurdardottir, S., Halldorsdottir, S. \& Bender, S. S. (2014). Consequences of childhood sexual abuse for health and well-being: gender similarities and differences. Scandinavian Journal of Public Health, 42, 278-286. DOI: 10.1177/1403494813514645
Vara da Infância e da Juventude — VIJ— (2012). Dados consolidados 2011. Disponível em http:// www.tjdft.jus.br/trib/vij/docVij/estatis/2010/ vij_estatisticaViolSex.pdf.

World Health Organization (1999). Child Maltreatment. Disponível em http://www.who.int/topics/ child_abuse/en/
Recebido: janeiro 30, 2015

Aprovado: abril 25, 2018 
